\title{
INDEX TO VOLUME 66
}

\section{RESEARCH ANNOUNCEMENTS}

Agmon, Shmuel. Maximum theorems for solutions of higher order elliptic equations, 77. Araki, S., James, I. M. and Thomas, Emery. Homotopy-abelian Lie groups, 324.

Aumann, R. J. Spaces of measurable transformations, 301.

Aumann, R. J. and Peleg, B. von Neumann-Morgenstern solutions to cooperative games without side payments, 173.

Baxter, Glen. Polynomials defined by a difference system, 187.

Beck, Anatole. Continuous flows with closed orbits, 305.

Bers, Lipman. Simultaneous uniformization, 94. Spaces of Riemann surfaces as bounded domains, 98.

Bharucha-Reid, A. T. On random solutions of Fredholm integral equations, 104.

Blum, J. R. and Hanson, D. L. On the mean ergodic theorem for subsequences, 308.

Boas, R. P., Jr. Beurling's test for absolute convergence of Fourier series, 24.

Borel, Armand. Commutative subgroups and torsion in compact Lie groups, 285.

Browder, William. Loop spaces of $H$-spaces, 316.

Brown, Morton. A proof of the generalized Schoenflies theorem, 74.

Butzer, P. L. and Tillmann, H. G. An approximation theorem for semi-groups of operators, 191.

Carlitz, L. Arithmetic properties of certain polynomial sequences, 202.

Chatterji, S. D. Martingales of Banach-valued random variables, 395.

van der Corput, J. G. On an identity of Block and Marschak, 28.

Fadell, Edward. The equivalence of fiber spaces and bundles, 50.

Fine, N. J. and Gillman, L. Extension of continuous functions in $\beta N, 376$.

Fong, Paul. Some properties of characters of finite solvable groups, 116.

Gandy, R. O. On a problem of Kleene's, 501.

Gillman, L. See Fine, N. J.

Gluck, Herman. The weak Hauptvermutung for cells and spheres, 282.

Goldberg, S. I. Conformal transformations of Kaehler manifolds, 54.

- Groups of automorphisms of almost Kaehler manifolds, 180.

Gould, H. W. A q-binomial coefficient series transform, 383.

Hanson, D. L. See Blum, J. R.

Harris, Bruno. $A$ generalization of $H$-spaces, 503.

Harrold, O. G., Jr. Locally peripherally euclidean spaces are locally euclidean, 194.

Hermann, Robert. Existence in the large of totally geodesic submanifolds of Riemannian spaces, 59.

On geodesics that are also orbits, 91.

$C$-W cell decompositions of symmetric homogeneous spaces, 126.

Hirsch, M. W. An exact sequence in differential topology, 322.

Hirschman, I. I., Jr. Hankel transforms and variation diminishing kernels, 40.

Hsiang, F. C. On differentiable functions, 382.

Isbell, J. R. A modification of Harsanyi's bargaining model, 70.

James, I. M. See Araki, S.

Katznelson, Yitzhak. A characterization of the algebra of all continuous functions on a compact Hausdorff space, 313.

Klingenberg, Wilhelm. Linear groups over local rings, 294.

Krabbe, G. L. Normal operators on the Banach space $L^{p}(-\infty, \infty)$. Part II. Unbounded transformations, 86. 
Laha, R. G. On a property of positive-definite functions, 388.

Lax, P. D. The scope of the energy method, 32.

Levinson, N. A canonical form for an analytic function of several variables at a critical point, 68.

A polynomial canonical form for certain analytic functions of two variables at a critical point, 366.

Lorentz, G. G. Approximation of smooth functions, 124.

Morse, Marston. A reduction of the Schoenflies extension problem, 113.

Ornstein, D. S. The differentiability of transition functions, 36.

On invariant measures, 297.

Peleg, B. See Aumann, R. J.

Raymond, Frank and Williams, R. F. Examples of p-adic transformation groups, 392.

Ree, Rimhak. A family of simple groups associated with the simple Lie algebra of type $\left(G_{2}\right), 508$.

Reifenberg, E. R. Solution of the Plateau problem for m-dimensional surfaces of varying topological type, 312 .

Rogers, K. and Straus, E. G. A class of geometric lattices, 118.

Rosenblatt, M. Asymptotic distribution of eigenvalues of block Toeplitz matrices, 320.

Rudin, Walter. Closed ideals in group algebras, 81.

Fourier-Stieltjes transforms of measures on independent sets, 199.

Schechter, Martin. Elliptic problems in which the boundary conditions do not form a normal set, 84 .

A general approach to boundary problems, 495.

Simon, A. B. Symmetry in measure algebras, 399.

Smale, Stephen. Morse inequalities for a dynamical system, 43.

The generalized Poincaré conjecture in higher dimensions, 373.

Stallings, J. R. Polyhedral homotopy-spheres, 485.

Stewart, T. E. Lifting the action of a group in a fibre bundle, 129.

Straus, E. G. See Rogers, K.

Thomas, Emery. See Araki, S.

Tillmann, H. G. See Butzer, P. L.

Titus, C. J. Combinatorial topology of an analytic function on the boundary of a disk, 489.

Trèves, François. Differential polnomials and decay at infinity, 184.

Wallace, A. D. Remarks on affine semigroups, 110.

Williams, R. F. See Raymond, Frank.

Wong, Y.-C. Clifford parallels in elliptic $(2 n-1)$-space and isoclinic n-planes in Euclidean $2 n$-space, 289.

Wright, E. M. Solution of the equation $(p z+q) e^{z}=r z+s, 277$.

Wright, F. B. On the existence of invariant measures, 506.

Yano, Kentaro. Conformal transformations in Riemannian and Hermitian spaces, 369.

Zeeman, E. C. Unknotting spheres in five dimensions, 198.

\section{RESEARCH PROBLEMS}

Brenner, J. L. Group theory, 275.

Brownell, F. H. Tauberian theorem problem, 275.

Stein, S. K. Partitions, 510.

Taussky, Olga. Discuss the location of the eigenvalues of the Jordan product of two hermitian matrices, 275.

\section{REPORTS OF MEETINGS AND MISCELLANEOUS ARTICLES}

Council and Board of Trustees-1959, 62.

Doctorates conferred in 1959, 156. 
Fejér, Leopold. See Szegö, Gabor.

Green, J. W. See Pitcher, Everett. See Youngs, J. W. T.

Huff, G. B. Reports of Meetings of the American Mathematical Society: The November Meeting in Winston-Salem, 2.

Meder, A. E., Jr. Report of the Treasurer, 65.

Pierce, R. S. Reports of Meetings of the American Mathematical Society: The November Meeting at Los Angeles, 3; The February Meeting in Tucson, 141; The April Meeting at Berkeley, 273; The June Meeting at Missoula, 360.

Pitcher, Everett. Reports of Meetings of the American Mathematical Society: The October Meeting in Cambridge, 1; The February Meeting in New York, 143.

Pitcher, Everett and Green, J. W. Reports of Meetings of the American Mathematical Society: The April Meeting in New York, 268.

Szegö, Gabor. Leopold Fejêr: In Memoriam, 1880-1959, 346.

Youngs, J. W. T. Reports of Meetings of the American Mathematical Society: The November Meeting in Detroit, 4; The April Meeting in Chicago, 272.

Youngs, J. W. T. and Green, J. W. Reports of Meetings of the American Mathematical Society: The Annual Meeting in Chicago, 133; The Summer Meeting in East Lansing, 465.

\section{BOOK REVIEWS}

Abhyankar, Shreeram. Ramification theoretic methods in algebraic geometry. E. C. Dade, 250.

Allendoerfer, C. B. See Nickerson, H. K.

Bachmann, Friedrich. Aufbau der Geometrie aus dem Spiegelungsbegriff. H. S. M. Coxeter, 263.

Baxter, Glen. See Kac, Mark.

Beaumont, R. A. See Fuchs, L.

Bochner, S. Lectures on Fourier integrals. Trans. by Morris Tenenbaum and Harry Pollard, 154.

Bourbaki, N. Elèments de mathêmatiques. Alex Rosenberg, 16.

- Formes sesquilinéaires et formes quadratiques. Irving Kaplansky, 266.

Buchsbaum, D. A. See Godemont, Roger.

Cairns, S. S. See Wallace, A. H.

Cesari, Lamberto. Asymptotic behavior and stability problems in ordinary differential equations. S. Lefschetz, 147.

The collected works of George Abram Miller, 155.

Coxeter, H. S. M. See Bachmann, Friedrich.

Dade, E. C. See Abhyankar, Shreeram.

Deuring, M. Die Klassenkorper der komplexen Multiplikation. L. J. Mordell, 13.

Dini, U. Opere. Vol. 4: Serie di Fourier. Vol. 5: Sviluppi in serie, 155.

Elliott, Joanne. See Smithies, F.

Floyd, E. E. See Conner, P. E.

Forsyth, A. R. Theory of differential equations, 365.

Fortet, R. See Kaplansky, Irving.

Fuchs, L. Abelian groups, R. A. Beaumont, 480.

Godemont, Roger. Topologie algébrique et thêorie des faisceaux. D. A. Buchsbaum, 14.

Goodier, J. N. and Hodge, P. G., Jr. Elasticity and plasticity, 153.

Green, L. W. See Willmore, T. J.

Grenander, U. See Probability and statistics.

Griffin, J. J. See Wigner, E. P.

Griffith, B. A. See Synge, J. L. 
Grosswald, Emil. See Jenkins, J. A.

Hall, Marshall, Jr. The theory of groups. Wilhelm Magnus, 144.

See Kaplansky, Irving.

Halmos, P. R. Lectures on ergodic theory, 484.

Hardy, G. H. Ramanujan, 155.

Hewitt, E. See Kaplansky, Irving.

Hille, Einar. Analytic function theory, Vol. 1. Guy Johnson, 253.

Hirsch, K. A. See Kurosh, A. G.

Hodge, P. G., Jr. See Goodier, J. N.

Hu, S.-T. Homotopy theory. W. S. Massey, 475.

Jenkins, J. A. Univalent functions and conformal mapping. Emil Grosswald, 19.

Johnson, Guy. See Hille, Einar.

Kac, Mark. Statistical independence in probability, analysis and number theory. W. J. LeVeque, 265.

Probability and related topics in physical sciences. Glen Baxter, 472.

Kantorovich, L. V. and Krylov, V. I. Approximate methods of higher analysis. Wilfred Kaplan, 146.

Kaplan, Wilfred. See Kantorovich, L. V.

Kaplansky, Irving. See Bourbaki, N.

Kaplansky, Irving, Hewitt, E., Hall, M. and Fortet, R. Some aspects of analysis and probability, 153.

Kreyszig, E. Differential geometry, 154.

Krylov, V. I. See Kantorovich, L. V.

Kullbach, Solomon. Information theory and statistics. Seymour Sherman, 472.

Kurosh, A. G. The theory of groups. Ed. and Trans. by K. A. Kirsch, 484 .

Landau, E. Grundlagen der Analysis, 484.

Lefschetz, S. See Cesari, Lamberto.

Leimanis, E. and Minorsky, N. Dynamics and nonlinear mechanics, 153.

LeVeque, W. J. See Kac, Mark.

Lorentz, G. G. See Pitt, H. R.

Lowe, P. G. See Novozhilov, V. V.

Luce, R. D. Individual choice behavior, a theoretical analysis. K. O. May, 259.

Magnus, Wilhelm. See Hall, Marshall, Jr.

Marden, Morris, See Specht, Wilhelm.

Massey, W. S. See Hu, S.-T.

May, K. O. See Luce, R. D.

Mendelson, Elliott. See Suppes, Patrick.

Mickle, E. J. See Whyburn, G. T.

Mikusinski, Jan. Rachunek Operatorów (Operational calculus). H. M. Schaerf, 260.

Miller, G. A. See Collected works of George Abram Miller.

Miller, K. S. Advanced complex calculus. E. C. Schlesinger, 257.

Minorsky, N. See Leimanis, E.

Mordell, L. J. See Deuring, M.

Nickerson, H. K., Spencer, D. C. and Steenrod, N. E. Advanced calculus. C. B. Allendoerfer, 148.

Novozhilov, V. V. The theory of thin shells. Trans. by P. G. Lowe; Ed. by J. R. M. Radok, 155.

Oxtoby, J. C. See Ulam, S. M.

Pitt, H. R. Tauberian theorems. G. G. Lorentz, 12.

Pollard, Harry. See Bochner, S. 
Probability and statistics. Ed. by U. Grenander, 154.

Proceedings of the International Congress of Mathematicians, 1958. Ed. by J. A. Todd, 365.

Radok, J. R. M. See Novozhilov, V. V.

Rainville, E. D. Special functions. I. M. Sheffer, 482.

Root, W. L. See Wiener, Norbert.

Rosenberg, Alex. See Bourbaki, N.

Salem, Raphael. See Zygmund A.

Schaerf, H. M. See Mikusinski, Jan.

Schlesinger, E. C. See Miller, K. S.

Schwartz, L. Théorie des distributions, 153.

Etude des sommes d'exponentielles, 153.

Severi, F. Il teorema di Riemann-Roch per curve, superficie e varieta, questioni collegate, 153.

Sheffer, I. M. See Rainville, E. D.

Sherman, Seymour. See Kullback, Solomon.

Smithies, F. Integral equations. Joanne Elliott, 256.

Specht, Wilhelm. Algebraische Gleichungen mit reellen oder komplexen Koeffizienten. Morris Marden, 63.

Spencer, D. C. See Nickerson, H. K.

Steenrod, N. E. See Nickerson, H. K.

Suppes, Patrick. Axiomatic set theory. Elliott Mendelson, 363.

Synge, J. L. and Griffith, B. A. Principles of mechanics, 154.

Szász, Gábor. Bevezetés a hâlóelmêletbe (Introduction to lattice theory), 365.

Tenenbaum, Morris, See Bochner, S.

Todd, J. A. See Proceedings of the International Congress of Mathematicians, 1958.

Ulam, S. M. A collection of mathematical problems. J. C. Oxtoby, 361.

Wallace, A. H. Homology theory on algebraic varieties. S. S. Cairns, 5.

Whyburn, G. T. Topological analysis. E. J. Mickle, 255.

Wiener, Norbert. Nonlinear problems in random theory. W. L. Root, 471.

Wigner, E. P. Groups theory, and its aplication to the quantum mechanics of atomic spectra. Trans. by J. J. Griffin, 154.

Willmore, T. J. An introduction to differential geometry, L. W. Green, 261.

Zassenhaus, H. J. The theory of groups, 153.

Zygmund, A. Trigonometric series. Raphael Salem, 6.

\section{INVITED ADDRESSES}

Ankeny, N. C., 268.

Besicovitch, A. S., 133.

Tangential properties of sets and arcs of infinite linear measure, 353.

Chern, S. S., 465.

Conner, P. E., 465.

Conner, P. E. and Floyd, E. E. Fixed point free involutions and equivariant maps, 416.

Dolph, C. L., 272.

Evans, Trevor, 2.

Floyd, E. E. See Conner, P. E.

Fuller, F. B., 274.

Halmos, Paul, 465.

Hunt, G. A., 1.

Karlin, Samuel, 360. 
Lang, Serge, 143.

- Some theorems and conjectures in diophantine equations, 240.

Lax, P. D., 268.

Motzkin, T. S., 142.

Rosenbloom, Paul, 133.

Ryser, H. J., 4.

Matrices of zeros and ones, 442 .

Samuel, Pierre, 272.

Smith, P. A. New results and old problems in finite transformation groups, 401.

Taussky, Olga. Matrices of rational integers, 327.

Todd, John, 3.

Whitehead, J. H. C., 4.

Wilder, R. L. A certain class of topological properties, 205. 